\title{
Spices: A Review on Diabetes Mellitus
}

\author{
Muhammad Hanif Mughal* \\ Homoepathic Clinic, Islamabad, Pakistan \\ *Corresponding author: Muhammad Hanif Mughal, Homoepathic Clinic, Islamabad, Pakistan
}

\begin{tabular}{|c|c|}
\hline ARTICLE INFO & ABSTRACT \\
\hline $\begin{array}{l}\text { Received: 幽 March 05, } 2019 \\
\text { Published: 幽 March 13, } 2019\end{array}$ & $\begin{array}{l}\text { Spices have been used widely in the different regions of the world due to the presence } \\
\text { of bioactive compounds such as thymoquinone, curcumin, eugenol, cinamaldehyde, allicin, }\end{array}$ \\
\hline $\begin{array}{l}\text { Citation: Muhammad Hanif Mughal. } \\
\text { Spices: A Review on Diabetes Mellitus. } \\
\text { Biomed J Sci \& Tech Res 15(5)-2019. } \\
\text { BJSTR. MS.ID.002770. }\end{array}$ & $\begin{array}{l}\text { exert health perspectives such as anticancer, anti-obesity, prevention from oxidative stress, } \\
\text { cardio-protective and anti-aging. They are provide help to prevent from the hyperglycemia } \\
\text { with insulin sensitizer effects in the brain. Spices polyphenols also act as an insulin mimetic } \\
\text { through enhancing the insulin activity in the brain. The current review article highlights } \\
\text { the phytochemical compositions of spices and their promising role against diabetes and }\end{array}$ \\
\hline $\begin{array}{l}\text { Keywords: Spices; Phytochemi- } \\
\text { cal Composition; Chemo-Preventive } \\
\text { Agent; Anti-Diabetic Role }\end{array}$ & $\begin{array}{l}\text { associated complications. These dietary regimes provides significant health to human } \\
\text { against various maladies. }\end{array}$ \\
\hline
\end{tabular}

\section{Introduction}

In addition to increasing the aroma and savor of foods, herbs and spices are widely utilized as preventive and curative agents in degenerative diseases in Middle East since approximately 5000 BC [1,2]. There are approximately 180 spice-derived bioactive components have been reported as effective against various degenerative human diseases. These spices showed an impressive biological responses and curing role against wide range of disorders. Many spices such as aromatic plants, oregano, sage, thymus, peppermint and garlic are cultivated worldwide and used to formulate the soft drinks, food confection, the ornamental industry, skin and hair care products, aromatherapy, and medicinal industry $[3,4]$. These are potential sources of biochemical substances such as polyphenols, flavonoids, quinines, polypeptides, terpenoids, alkaloids, or their oxygen-substituted by products and behaved like as antioxidants. They are cherished mixtures of terpenoids like geraniol, linalool, menthol, $\alpha$-terpineol, borneol, citronnillol, thujanol, and phenols including carvacrol, thymol, gaiacol, and eugenol and aromatic aldehydes i.e. cuminal, cinnamaldehyde, and phellandral. These are extracted from different portions of the plants such as buds, seeds, flowers, twigs, leaves, wood, bark, and roots [5]. They guard the body from harm caused by production of reactive oxygen species and oxidative stress and inducing cytochrome. Besides, spices suppress the oxidative rancidity, slow down the development of off-flavor and retardation of microbial growth in food containing products such as snack foods and meat products. The essential oils are usually mined by steam purification and exhibited cytotoxic effects on living cells due to the existence of phenols, aldehydes and alcohols [6].

\section{Turmeric}

Turmeric (Curcuma longa Zingiberaceae) is the potential source of at least 235 compounds, primarily phenolic compounds and terpenoids which have been identified such as diarylpentanoids, diarylheptanoids, sesquiterpenes, monoterpenes, triterpenoids, diterpenes, sterols, and alkaloid etc. These are yellow coloring compounds commonly used in food-based products as main active compounds [7]. A study reported by Murugan and Pari [8], they investigated the preventive role of curcumin against diabetic nephropathy in streptozotocin induced rats. Curcumin suppresses the vascular endothelial growth factor, pro-inflammatory cytokines (IL-1b), NFkB signaling, and increasing activity of chaperone molecules. The previous investigations of Kuroda et al. [9] evaluated that ethanolic extract of turmeric considerably inhibited the glucose level enhancement in hyperglycemic KK-A(y) mice. These extract polyphenols stimulated the human adipocyte diversity in a dose dependent manner and shown human Peroxisome Proliferator Activated Receptor (PPAR) gamma ligand-binding activity in a 
GAL4-PPAR-gamma whimsy assay. Arun and Nalini [10] proposed the anti-hyperglycemia role of turmeric and its bioactive ingredient curcumin in a variety of animal models due to their antioxidant potential.

Curcumin reduced the glucose level, Free Fatty Acids (FFAs), glycosylated haemoglobin, triglyceride, total cholesterol, and lipid per-oxidation levels whereas enhanced the hepatic glycokinase activity and plasma insulin points in C57BL/Ks- $\mathrm{db} / \mathrm{db}$ diabetic rats. Similarly, Jang et al. [11] determined that curcumin normalized the lipid blood profile along with attenuation in insulin resistance, and reduction in leptin levels in hamsters fed high fat rats. Furthermore, turmeric lowered blood sugar glucose level, reduced TNF- $\alpha$ levels, and improved the insulin sensitivity in male sprague dawley rats. It also improved glucose tolerance, amplified adipose tissue adiponectin making, lowered insulin conflict, and pro-inflammatory cytokines with IL-1 $\beta$, TNF- $\alpha$, and partial white adipose tissue macrophage permeation in obese, leptin-deficient ob/ob C57 BL/6J rats [12]. It also reduces diabetes problems such as nephrologic, ophthalmologic, and cardiovascular. Curcumin intervals cataract maturation and decreases renal lesions in Streptozotocin (STZ) encouraged diabetes mice. The supplementation of $6 \mathrm{~g} /$ day turmeric improved the postprandial serum insulin levels in mice, whilst lowered the plasma glucose levels. Curcuminoids amended endothelial dysfunction related with reductions in provocative cytokines and indicators of oxidative strain in T2DM rats for eightweeks [13] (Table 1).

Table 1: Anti-diabetic role of spices.

\begin{tabular}{|c|c|c|}
\hline Spices & Mechanisms & References \\
\hline \multirow{5}{*}{ Turmeric } & $\begin{array}{l}\text { Suppressed the vascular endothelial growth factor, pro-inflammatory cytokines (IL-1b), NFkB signaling, and } \\
\text { increasing activity of chaperone molecules. }\end{array}$ & [8] \\
\hline & $\begin{array}{l}\text { Inhibited the glucose level enhancement } \\
\text { Stimulated the human adipocyte diversity }\end{array}$ & [9] \\
\hline & $\begin{array}{l}\text { Reduced the glucose level, Free Fatty Acids (FFAs), glycosylated hemoglobin, triglyceride, total cholesterol, and } \\
\text { lipid per-oxidation levels } \\
\text { Enhanced the hepatic glycokinase activity and plasma insulin }\end{array}$ & {$[10]$} \\
\hline & Improved the hepatic glycogen equal \& permitted amino acid content & \multirow[b]{2}{*}[18]{} \\
\hline & $\begin{array}{l}\text { Lowered glucose and triglyceride concentration } \\
\text { Inhibited superoxide formation and lipid per-oxidation } \\
\text { Blocked the AGEs synthesis }\end{array}$ & \\
\hline Garlic & $\begin{array}{l}\text { Modified the activities of hemoglobin coenzyme-A reductase and liver hexokinase glucose-6-phosphatase } \\
\text { Enhanced the liver glycogen and free amino acids contents } \\
\text { Triggered Lecithin- Cholesterol Acyltransferase (LCAT), glucose-6-phosphatase, and hexokinase, 3-Hydroxy- } \\
\text { 3-Methyl-Glutaryl (HMG) Co-A reductase }\end{array}$ & {$[19]$} \\
\hline Ginger & $\begin{array}{c}\text { Showed inhibitory effect on serotonin-induced hyperglycemic and hypoinsulinamia } \\
\text { Decreased the plasma malondialdehyde concentration and increased the total antioxidant capacity as well as } \\
\text { erythrocyte antioxidant enzyme activities (GSH-Px and SOD). }\end{array}$ & {$[23]$} \\
\hline Cinnamon & $\begin{array}{l}\text { Improved the insulin receptor function through starting the enzyme } \\
\text { Suppressed the enzyme (insulin-receptor phosphatase) and enhanced insulin sensitivity }\end{array}$ & {$[26,27]$} \\
\hline Clove & $\begin{array}{l}\text { Lowered blood sugar level, and decreased cholesterol, triglycerides \& low mass lipoprotein } \\
\text { Enhanced high mass protein and redeveloped the pancreatic } \beta \text {-cells } \\
\text { Lowered 3-Hydroxyl-3-Methylglutaryl Coenzyme A Reductase (HMG-CoA reductase activity) }\end{array}$ & \\
\hline \multirow[b]{2}{*}{ Cumin } & $\begin{array}{l}\text { Lowered the body weight, blood urea and area beneath the glucose lenience curve } \\
\text { Inhibited the aldose reductase and alphaglucosidase enzymes activities }\end{array}$ & {$[38]$} \\
\hline & $\begin{array}{l}\text { Decreased the absorption of glucose from intestine } \\
\text { Lowered glucose transport processes and serum glucose level } \\
\text { Inhibited } \alpha \text {-glucosiadse, and Aldose reductase }\end{array}$ & {$[39]$} \\
\hline
\end{tabular}

\section{Garlic}

Garlic (Allium sativum L.) is the most widely studied and oldest cultivated plant and has been used in food based products for over
4000 years. The garlic word was derived from the Anglo-saxon 'gar-leac' or spike plant [14]. It belongs to Amaryllidaceae family and consists of almost $65 \% \mathrm{H}_{2} \mathrm{O}, 28 \%$ starches, $2.3 \%$ organosulfur compounds, $2 \%$ protein, $1.5 \%$ fiber, and $1.2 \%$ amino acids (major 
Arginine). It comprises more than 200 biochemical compounds and additional key compounds are allicin, alliin, cycroalliin, Diallyl Disulphide (DADS), and ajoene, $\beta$-phellandrene, geraniol, citral, a-phellandrene, linalool and enzymes (allinase, myrosinase, and peroxidase) [15]. It is also promising source of flavonoids, vitamins $\left(A, B_{1}, C\right)$, and minerals such as potassium, phosphorous, manganese, selenium, sulphur, magnesium, calcium, sodium, iron, germanium, and trace iodine. It also consists of 17 amino acids with eight essential amino acids. Throughout metabolism, garlic is transformed into various metabolites such as allyl-mercaptan, n-acetyl-s-allyl cysteine, diallyl sulfoxide, diallyl sulfide, diallylsulfone, diallyl disulfide, and allylmethyl sulfide [16]

Diabetes is growing developing metabolic public health disorder and linked with abnormal levels of glucose in the bloodstream. It is an estimated to be 333 million people of diabetic by 2025. There are lot of natural phytochemicals are being disbursed by the patient as well as healthy person. These nutrients are used for treatment of the diabetes disease due to raw consumption, easy availability, low cost and least side effects [17]. The oral administration of synthetic oral anti-hypoglycemic agents are more operational to lowers the glucose level but on other side they produced the harmful effects in rats. Among these, the oral supplementation of the whole garlic extract has improved the hepatic glycogen equal \& permitted amino acid content and dropped the glucose and triglyceride concentration in high sucrose-fed rats. Similarly, garlic extract depresses the blood sugar level, inhibits superoxide formation and lipid per-oxidation in rats. S-allyl cysteine is a potent antioxidant which blocked the AGEs synthesis that augmented the insulin release effect and hepatic metabolism [18]. Allicin controls the blood sugar level in serum and modifies the activities of haemoglobin coenzyme-A reductase and liver hexokinase glucose-6-phosphatase towards normal rats.

Likewise, supplementation of allicin to rabbits crucially enhanced the liver glycogen and free amino acids contents that overwhelms the triglycerides level, liver serum proteins, and Fasting Blood Sugar (FBS) as compared to high sucrose-fed diet mice. The administration of S-Methyl Cysteine Sulfoxide (SMCS) and diallylthiosulfinate to alloxan induced diabetic rats that triggers many enzymes including Lecithin- Cholesterol Acyltransferase (LCAT), glucose-6-phosphatase, and hexokinase, 3-Hydroxy3-Methyl-Glutaryl (HMG) Co-A reductase [19]. Osman et al. [20] used daily intra-peritoneal management of different concentrations of allicin such as little dose $8 \mathrm{mg} / \mathrm{kg}$ or extraordinary dose $16 \mathrm{mg} /$ $\mathrm{kg}$ but more with high dose up to 29 days to type 1 diabetic mice. They efficiently lessen the levels of anti-islet cell antibodies ICA, elevated pan innate cells marker (CD11b), the elevated pan B cell marker (CD19), and elevated pan T cell marker (CD90). These markers are improved due to autoimmunity process and were significantly lowered after the allicin supplementation; depressed level of insulin owing to injured langerghans key cell which was considerably greater in the serum owing to fixing tissue process after allicin application. Garlic and its bio-active component accomplish mechanistically hypoglycemic role through releasing of bound insulin or improving insulin sensitivity and high pancreatic excretion of insulin from $\beta$-cells. S-allyl cysteine re-establishes its function in streptozotocin-diabetic rats through avoiding free radicals formation and also modulating the NADPH oxidase [21].

\section{Ginger}

Ginger (Zingiber officinale) belongs to the family Zingiberaceae and has been used all over the world as a natural food component to arrange food based products. It consists of carbohydrates 60 $70 \%$, water $9-12 \%$, protein $9 \%$, ash $8 \%$, fatty oil $3-6 \%$, crude fiber $3-8 \%$, and volatile oil $2-3 \%$. It is also promising source of essential volatile oils including 30-70\% alpha-zingiberene, $15-20 \%$ beta-sesquiphellandrene, 10-15\% beta-bisabolene, curcumene, betaphellandrene, camphene, zingiberene, respectively [22]. A alike result was reported by Akhani et al. [23] who determined that ginger juice exhibits hypoglycemic doings in both usual and streptozotocin-induced diabetic mice, through its inhibitory effect on serotonin-induced hyperglycemic and hypoinsulinamia.

On the other end, the management of ginger extract to STZinduced diabetic mice caused substantial decreases in plasma malondialdehyde concentration and significant increases in total antioxidant capacity as well as erythrocyte antioxidant enzyme activities (GSH-Px and SOD). The decrease in malondialdehyde level in ginger-treated diabetic rats, is in conventionality with previously reported data. It was found that administering ginger powder to streptozotocin-induced diabetic rats caused vital decrease in TBARS levels. It was also mentioned that decreases in TBARS levels may upsurge the activity of glutathione peroxidase in treated mice. Thus, an increase of plasma antioxidant capacity caused diminutions plasma-free radical and lipid peroxidation (MAD), when overwhelming herbal extracts comprising antioxidants [24].

\section{Cinnamon}

Cinnamon (Cinnamomum Zeylanicum) is mainly used in the food based products such as perfumes, and medicines due to its fragrance. Cinnamon is bulging source of cinnamaldehyde and trans-cinnamaldehyde essential oils that showed various health endorsing properties. It is gifted source of several bioactive components i.e. cinnamaldehyde, cinnamic acid, cinnamate, and several essential oils including trans-cinnamaldehyde, cinnamyl acetate, eugenol, L-borneol, b-caryophyllene, caryophyllene oxide, E-nerolidol, L-bornyl acetate, $\alpha$-terpineol, $\alpha$-cubebene, $\alpha$-thujene and terpinolene [25]. In vitro studies Broadhurst et al. [26] compared 49 spices, herbs, and medicinal plant extracts for their insulin-like action in an in vitro study and determined that aqueous extracts of cinnamon showed 20 times more antioxidant potential as compared to other compounds. It also improved the insulin receptor function through starting the enzyme that bases insulin to bind to cells and suppressing the enzyme (insulin-receptor 
phosphatase), important to most phosphorylation of the insulin receptor that is linked with enhanced insulin sensitivity.

The Methylhydroxychalcone Polymer (MHCP) in cinnamon has capability to act as insulin mimetic in 3T3-L1 adipocytes [27]. The MHCP down regulated glycogen synthase kinase-3 $\beta$ (GSK-3 $\beta$ ) activity and stimulated the autophosphorylation of the Insulin Receptor (IR), glycogen synthesis, Glycogen Synthase (GS) activity, and up regulated glucose endorsement in 3T3-L1 adipocytes. The glycogen synthesis inspiration is done via Phosphatidylinositol (PI) 3-kinase dependent pathway. Anderson et al. [28] assessed the in vitro insulin-potentiating activity of procyanidin type-A polymers (monomers) of cinnamon in epididymal fat cells.

\section{Clove}

The herbs and spices excite the pancreas to interfere with dietary glucose absorption, produce and reinvent insulin, and insulin careful action of the bioactive ingredients. Clove is prominent source of essential oils such as caryophyllene, eugenol, alpha-terpinyl acetate, alpha-humulene, methyl eugenol, eugenyl, naphthalene, actyl eugenol, heptanone, sesquiterpenes, chavicol, vanillian, and methyl salicylate pinene and used in many food based products [29]. Diabetes mellitus is a chronic human health syndrome that associated with high abstaining blood sugar level and lipoprotein complications. During cellular metabolism, production of reactive oxygen species, environmental factors and life style injury the cell membranes that caused diabetes. Streptozotocin induced diabetic rats increase the oxidative stress, oxidized LDL-cholesterol and other lipoproteins problems. During oxidation, LDL-cholesterol is quickly absorbs and damages through macrophages and improves the degradation of un-oxidized LDL-cholesterol [30].

Clove has mimetic effect on hypolipidemia through following mechanism such as lowering blood sugar level, decreasing cholesterol, triglycerides \& low mass lipoprotein, and enhancing high mass protein. It redevelops the pancreatic $\beta$-cells through lowering 3-hydroxyl-3-methylglutaryl coenzyme A reductase (HMG-CoA reductase activity) [31].

\section{Basil}

The basil (Ocimum sanctum) belongs to family Labiatae. It is gifted source of essential oil such as octane, $\alpha$-Thujene, ethyl 2-methyl butyrate, $\alpha$-pinene, (Z)-3-hexanol, myrecene, $\beta$-pinene, limocene, ethyl benzene, allo-oc-imene, terpiniolene, $\alpha$-cubebene, butyl-benzene, eugenol, linalool, carvacrol, borneol, methyl eugenol, iedol, humulene oxide, germacrene-D, $\tau$-cadinol, $\alpha$-guaiol, (EZ)famesol, $\alpha$ - bisbolol, elemol, cissesquisainene hydrate, selin-11-en4 - $\alpha$-ol, tetradecanal, and 14-hydroxy- $\alpha$-humulene. These bioactive ingredients depends on the processing \& storage conditions, type of soil, and harvesting time [32].

Vats et al. [33] determined that basil vital oil is known for its therapeutic benefits to significantly decrease the abstaining blood sugar level, reduction in uronic acid, entire cholesterol, triglyceride and total lipid in both usual and alloxanized mice. Similarly, the ethanolic extract of basil leaves reduced the glucose along with improved in the renal glycogen gratified, whilst hepatic glycogen and skeletal muscle stages are lowered in streptozotocin-diabetic mice. Lemhadri et al. [34] evaluated, that use of basil extract $(0.2$ $\mathrm{g} / \mathrm{kg}$ ) for 30 days affected a substantial decrease in the plasma glucose level, whilst renal glycogen content improved 10 fold while skeletal muscle and hepatic glycogen levels lowered by 68 and $75 \%$ respectively in streptozotocin diabetic rats as associated to resistor. The earlier outcomes of Rai et al. [35] determined the possibility of supplementation of basil powder on glycemic control in 27 noninsulin dependent diabetes mellitus subjects. They significantly lowered sugar level (20.8\%) after $30^{\text {th }}$ day.

\section{Cumin}

Cumin (Nigella sativa. $L$ ) belongs to family Ranunculaceae and is an excellent source of thymoquinone, thymol and dithymoquinone compounds. These compounds are operative against cardiovascular diseases, different types of human cancers, diabetes complications, kidney disease, asthma etc [36]. In anti-diabetic effects, cumin considerably enhanced the area beneath the glucose acceptance curve and hyperglycemic peak in rabbits. The methanolic excerpt of cumin seeds lower the blood glucose and overwhelms the creatinine, blood urea nitrogen, glycosylated haemoglobin, and better-quality serum glycogen and insulin contents in Streptozotocin (STZ) and alloxan diabetic rats [37]. In vitro, cumin prohibited $\alpha$-crystallin, glycation of whole soluble protein, and behind the development and ripening of STZ-induced cataract in rats. It prohibited the loss of chaperone activity and also lessened the organizational changes of $\alpha$ - crystalline (long-lived protein) in lens of diabetic rats. The management of cumin lowered the hyperglycemia and glucosuria attended by an enhancement in body weight, blood urea and compact evacuation of urea and creatinine for eight-week in STZdiabetic rats.

It also meaningfully lowered the area beneath the glucose lenience curve. Cuminaldehyde also inhibited the aldose reductase and alphaglucosidase enzymes activities [38]. From the results of a study showed that treatment with cumin 50,100,200 gm/ $\mathrm{kg}$ of forage lead to decrease serum glucose level when compare with diabetic control group. The effect of cumin may be due to its ability to inhibit $\alpha$-glucosidase. This enzyme is answerable about degradation of disaccharide like sucrose, and polysaccharide like starch to monosaccharides referred that treatment with polyphenolic compound extracted from black cumin in rats leads to decrease serum glucose level as a result to the effect of $\alpha$-glucosiadse. The hypoglycemic outcome of cumin may be due to presence of flavones, which found that flavones have an effect to hinder $\alpha$-glucosiadse, and Aldose reductase, also flavones cause decrease absorption of glucose from intestine through reduction in glucose transport processes that rest on calcium. Other possible 
mechanism to decrease of serum glucose level due to cumin management may be due to the presence of cuminaldehyde, this substance have capability to inhibit $\alpha$-glucosiadse, and Aldose reductase, and these enzymes works to avoid rise of insulin level in the body [39].

\section{Rosemary}

Rosemary (Rosmarinus officinalis L.) fit into the family Lamiaceae and is being used as a food flavoring agent due to its powerful antimicrobial, anticancer, anti-diabetic activities and also as a chemo-preventive agent. It constitutes a wide variety of bioactive phytochemicals such as, carnosic acid, carnosol, 7-methylepirosmanol, rosmanol, rosmadial, isorosmanol, rosmaridiphenol, caffeic acid, and rosmariquinone, approximately $90 \%$ of the antioxidant activity of rosemary is owing to the presence of carnosol and camosic acid [40]. The oral supplementation of rosemary leaf extract lowers the glucose level, total cholesterol, triglycerides, LDL-cholesterol and enhances the HDL-cholesterol. As a hypolipidemic role of rosemary, it is also tortuous in exclusion of the lipids from the body [41]. The supreme important phenolic mixtures such as caffeic, ferulic acids, ellagic, rosmarinic acid, sesamol, and vanillin suppress the atherosclerosis. Additionally, rosemary compounds have cardio protective abilities to guard LDL from oxidative alteration in mice. Similarly, carnosic acid (derived from rosemary) suppressed the LDL oxidation in a dose reliant on manner [42].

\section{Oregano}

The oregano (origanum vulgare) is an important genus of the Lamiaceae family and is broadly used all over the world. It consists of oleanolic acid, flavonoids, ursolic acid, caffeic, terpinene, hydroquinones, p-cymene, carvacrol, lithospermic, thymol, and rosemarinic acids, and tannins. Phenolic mixtures have $71 \%$ of the total oil [43]. In this context, Talpur et al. [44] investigated that oregano extract improves glucose concentration through growing insulin sensitivity. It exerts the anti-hyperglycemic role owing to the interference on stimulation of glucose application or captivation of dietary starches in small intestine or by peripheral tissues. Likewise, Takeda et al. [45] presented the anti-hyperglycemic activity of oregano phenolic glucosides due to inhibition of tubular glucose re-absorption and a decrease in the intestinal absorption of glucose. Similarly, supplementation of aqueous extract of oregano leaves significantly lowered the neck of glycosylated Haemoglobin (HbA1C) (High level of HbAlc indicates DM) in rats.

The depressed level of $\mathrm{HbA1C}$ in the oregano leaf extract preserved diabetic mice may be due to stimulating the insulin level from the remainder pancreatic $\beta$-cells. Moreover, Broadhurst et al. [46] evaluated that oregano extracts showed the hypoglycemic effect through civilizing glucose and insulin metabolism. One of study conducted by Vinay et al. [47], the administration of oregano showed a substantial increment in muscle and liver glycogen level in diabetic rats. The improvement in hepatic glycogen contents may be due to amplified level of insulin that lowered glycogenolysis \& gluconeogenesis, and enhanced glycogenesis. Hence, the hypoglycemic effect of oregano may be due to improve in glycogen storage and insulin secretion, protection of remaining pancreatic $\beta$ cells, respectively [37]. The management of aqueous extract of oregano leaves lessen the concentration of blood glucose in Streptozotocin (STZ) induced diabetic mice without affecting basal plasma insulin absorptions [48].

\section{Coriander}

Plants and their bioactive compounds exhibited a capable role to curtail various human ailments. Phytotherapy is another major and well known and alternative medicinal (CAM) therapeutic modality. It is very effective to alleviate the human health related ailments without side effects [49]. The coriander (Coriandrum sativum) belongs to apiaceae and being used as a curative agent in many food based yields for long centuries. The ingesting of nutraceutical compounds of coriander plays a prominent role in health curative functions of humans. It is capable source of resin, oxalic acid, volatile oils and carbazole alkaloids that potential source of bicyclomahanimbicine and mahanimbicine. Coriander is comprised of linalool (60-80 percent), $\gamma$-terpinene (1-8 percent), terpinen-4-ol (trace-3 percent), hydrocarbons; $\rho$-cymene (trace-3.5 percent), ketones (7-9 percent) and esters [50]. There is another mechanism involved in hypoglycemic activity of rats such as lowered the cholesterol biosynthesis through suppression of 3-hydroxy-3-methylglutaryl coenzyme A reductase (cholesterol biosynthesis enzyme), 2- Increase in Lecithin-Cholesterol-Acyl Transferase (LCAT) activity, 3 Improved the poverty of cholesterol to fecal bile acids and impartial sterols. The hypotriglyceridemic effect of coriander through suppression of lipogenic enzymes or inhibiting hormone-sensitive tissue lipases, activating LCAT and tissues lipases [50].

\section{Conclusion}

Spices have been reported as significant source of bioactive compounds to cure the human diseases. These spices and their compounds have been also attested for diabetes complications in animal trials. Diabetes mellitus is a chronic disorder and associated with insulin deficiency. Beta cells from pancreas secretes the insulin which normalize the blood sugar level. On other side, spices polyphenols significantly lowered the enhanced blood sugar levels and lipid peroxidation in streptozotocin induced diabetic. They maintain and restore the antioxidant enzyme levels. They prevent from hyperglycaemia-induced oxidative tissue damage and cataract formation.

\section{References}

1. Chang J (2000) Medicinal herbs: drugs or dietary supplements? Biochem Pharmacol 59(3): 211-219.

2. Li XM, Srivastava K (2006) Traditional Chinese medicine for the therapy of allergic disorders. Curr Opin Otolaryngol Head Neck Surg 14(3): 191196. 
3. Moon DO, Kim MO, Lee JD, Choi YH, Kim GY (2010) Rosmarinic acid sensitizes cell death through suppression of TNF-alpha-induced NFkappaB activation and ROS generation in human leukemia U937 cells. Cancer Lett 288(2): 183-191.

4. Kadri A, Zarai Z, Chobba IB, Bekir A, Gharsallah A, Damakm N, Gdoura M (2011) Chemical constituents and antioxidant properties of Rosmarinus officinalis $L$. essential oil cultivated from South-Western Tunisia. J Med Plants Res 5(25): 5999-6004.

5. Perumalla AVS, Hettiarachchy NS (2011) Green tea and grape seed extracts Potential applications in food safety and quality. Food Res Int 44(4): 827-839.

6. Sacchetti G, Maietti S, Muzzoli M, Scaglianti M, Manfredini S, et al. (2005) Comparative evaluation of 11 essential oils of different origin as functional antioxidants, antiradicals and antimicrobials in foods. Food Chem 91(4): 621-632.

7. Henrotin Y, Clutterbuck AL, Allaway D, Lodwig EM, Harris P, et al. (2010) Biological actions of curcumin on articular chondrocytes. Osteoarthritis and cartilage/OARS Osteo Res Soc 18(2): 141-149.

8. Murugan P, Pari L (2006) Effect of tetra hydrocurcumin on plasma antioxidants in streptozotocin-nicotinamide experimental diabetes. J Basic Clin Physiol Pharmacol 17(4): 231-244.

9. Kuroda M, Mimaki Y, Nishiyama T, Mae T, Kishida H, et al. (2005) Hypoglycemic effects of turmeric (Curcuma longa L. rhizomes) on genetically diabetic KK-Ay mice. Biol Pharm Bull 28(5): 937-939.

10. Arun N, Nalini N (2002) Efficacy of turmeric on blood sugar and polyol pathway in diabetic albino rats. Plant Foods Hum Nutr 57(1): 41-52.

11. Jang EM, Choi MS, Jung UJ, Kim MJ, Kim HJ, et al. (2008) Beneficial effects of curcumin on hyperlipidemia and insulin resistance in high-fat-fed hamsters. Metabolism 57(11): 1576-1583.

12. Weisberg SP, McCann D, Desai M, Rosenbaum M, Leibel RL, et al. (2003) Jr. Obesity is associated with macrophage accumulation in adipose tissue. J Clin Invest 112(12): 1796-1808.

13. Usharani P, Mateen AA, Naidu MU, Raju YS, Chandra N (2008) Effect of NCB-02, atorvastatin and placebo on endothelial function, oxidative stress and inflammatory markers in patients with type 2 diabetes mellitus: A randomized, parallel-group, placebo-controlled, 8-week study. Drugs RD 9(4): 243-250.

14. Cerella C, Dicato M, Jacob C, Diederich M (2011) Chemical properties and mechanisms determining the anti-cancer action of garlic-derived organic sulfur compounds. Anticancer Agents Med Chem 11(3): 267271.

15. Iciek M, Kwiecień I, Włodek L (2009) Biological properties of garlic and garlic-derived organosulfur compounds. Environ Mol Mutagen 50(3): 247-265.

16. Bungu L, Van de Venter M, Frost C (2008) Evidence for an in vitro anticoagulant and antithrombotic activity in Tulbaghia violacea. African J Biotechnol 7(6): 681-688.

17. Elliott JA, Jackson S, King S, McHugh R, Docherty NG, et al. (2015) GuT hormone suppression increases food intake after esophagectomy with gastric conduit reconstruction. Ann Surg 262(5): 824-830.

18. Khan V, Najimi AK, Akhtar M, Aqil M, Mujeeb M, et al. (2012) A pharmacological appraisal of medicinal plants with antidiabetic potential. J Pharm Bioallied Sci 4(1): 27-42.

19. Noor A, Bansal VS, Vijayalakshmi MA (2013) Current update on antidiabetic biomolecules from key traditional Indian medicinal plants. Curr Sci 104(6): 721.

20. Osman M, Adnan A, Salmah BN, Alashkham F (2012) Allicin has significant effect on autoimmune anti-islet cell antibodies in type 1 diabetic rats. Pol J Pathol 63(4): 248-254.

21. Yang J, Wang T, Yang J, Rao K, Zhan Y, et al. (2013) S-allyl cysteine restores erectile function through inhibition of reactive oxygen species generation in diabetic rats. Androl 1(3): 487-494.
22. Kumar P, Mishra S, Malik A, Satya S (2011) Repellent, larvicidal and pupicidal properties of essential oils and their formulations against the house fly, Musca domestica. Med Vet Entomol 25(3): 302-310.

23. Akhani SP, Vishwakarma SL, Goyal RK (2004) Anti-diabetic activity of Zingiber officinale in streptozotocin-induced type I diabetic rats. J Pharm Pharmacol 56: 101-105.

24. Sozmen EY, Soxmen B, Delen Y, Onat T (2001) Catalase superoxide dismutase (SOD) and catalase/paraoxonase (PON) ratios may implicate poor glycemic control. Arch Med Res 32: 283-287.

25. Yeh HF, Luo CY, Lin CY, Cheng SS, Hsu YR, et al. (2013) Methods for thermal stability enhancement of leaf essential oils and their main constituents from indigenous cinnamon (Cinnamomum osmophloeum). J Agric Food Chem 61(26): 6293-6298

26. Broadhurst CL, Polansky MM, Anderson RA (2000) Insulin-like biological activity of culinary and medical plant aqueous extracts in vitro. J Agric Food Chem 48: 849-52.

27. Jarvill-taylor KJ, Anderson RA, Graves DJ (2001) A hydroxychalcone derived from cinnamon functions as a mimetic for insulin in 3T3-11 adipocytes. J Am Coll Nut 20(4): 327-336

28. Anderson RA, Broadhurst GL, Polansky MM, Schmidt WF, Khan A, et al. (2004) Isolation and characterization of polyphenol type-Apolymers from cinnamon with insulin-like biological activity. J Agric Food Chem 52(1): 65-70.

29. Sengupta A, Ghosh S, Bhattacharjee S (2005) Dietary cardamom inhibits the formation of azoxymethane-induced aberrant crypt foci in mice and reduces COX-2 and iNOS expression in the colon. Asian Pac J Cancer Prev 6(2): 118-22.

30. Prakash P, Gupta N (2005) Therapeutic uses of Ocimum sanctum Linn (Tulsi) with a note on eugenol and its pharmacological actions: a short review. Indian J Physiol Pharmacol 49(2): 125-131.

31. Srinivasan K (2005) Spices as influencers of body metabolism: An overview of three decades of research. Food Res Int 38: 77-86.

32. Kothari SK, Bhattacharya AK, Ramesh S (2004) Essential oil yield and quality of methyl eugenol rich Ocimum tenuiflorum L. f. (syn. O. sanctum $L$.) grown in South India as influenced by method of harvest. J Chromatogr 1054: 67-72.

33. Vats V, Grover JK, Rathi SS (2002) Evaluation of antihyperglycemic and hypoglycemic effect of $T$ foenumgraecum, $O$ sanctum and $P$ marsupium in normal and alloxanized diabetic rats. J Ethn 79(1): 95-100.

34. Lemhadri A, Zeggwagh NA, Maghrani M, Jouad H, Eddouks, M (2004) Anti-hyperglycaemic activity of the aqueous extract of Origanum vulgare growing wild in Tafilalet region. J Ethn 92(2-3): 251-256.

35. Rai V (1997) Effect of Tulsi (O sanctum) leaf powder supplementation on blood sugar levels, serum lipids and tissue lipids in diabetic rats. J Ethn 50: 9-16.

36. Lutterodt H, Luther M, Slavin M, Yin JJ, Parry J, et al. (2010) Fatty acid profile, thymoquinone content, oxidative stability, and antioxidant properties of cold-pressed black cumin seed oils. LWT-Food Sci Tech 43: 1409-1413.

37. Jagtap AG, Patil PB (2010) Antihyperglycemic activity and inhibition of advanced glycation end product formation by Cuminum cyminum in streptozotocin induced diabetic rats. Food Chem Toxicol 48(8-9): 2030 2036.

38. Lee HS (2005) Cuminaldehyde: aldose reductase and alpha-glucosidase inhibitor derived from Cuminum cyminum L. seeds. J Agric Food Chem 53(7): 2446-2450.

39. Ani MCV, Varadaraj AN (2006) Antioxidant and antibacterial activities polyphenolic compounds from bitter Cumin (Cuminum nigrum L.). Eur Food Res Technol 224(1): 109-115.

40. Saber AS, Hawazen AL (2012) Protective Effect of Rosemary (Rosmarinus officinalis) Leaves Extract on Carbon Tetrachloride-Induced Nephrotoxicity in Albino Rats. Life Sci J 9: 779-785. 
41. Naidu KA, Thippeswamy NB (2002) Inhibition of human lowdensity lipoprotein oxidation by active principles from spices. Mol Cell Biochem 229: $19-23$

42. Nofer JR, Kehrel B, Fobker M, Levkau B, Assmann G, Von EA (2002) HDL and arteriosclerosis: beyond reverse cholesterol transport Atherosclerosis 161: 1-16.

43. Tuncer E, Unver-Saraydin S, Tepe B, Karadayi S, Ozer H, et al. (2013) Antitumor effects of Origanum acutidens extracts on human breast cancer. J Buon 18(1): 77-85.

44. Talpur N, Echard B, Ingram C, Bagchi D, Preuss H (2005) Effects of a novel formulation of essential oils on glucose-insulin metabolism in diabetic and hypertensive rats: A pilot study. Diabetes Obes Metab 7(2): 193-199.

45. McCue P, Vattem D, Shetty K (2004) Inhibitory effect of clonal oregano extracts against porcine pancreatic amylase in vitro. Asia Pac J Clin Nutr 13(4): 401-408.

\section{ISSN: 2574-1241}

DOI: 10.26717/BJSTR.2019.15.002770

Muhammad Hanif Mughal. Biomed J Sci \& Tech Res

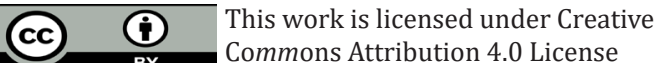

Submission Link: https://biomedres.us/submit-manuscript.php
46. Broadhurst CL, Polansky MM, Anderson RA (2000) Insulin-like biological activity of culinary and medical plant aqueous extracts in vitro. J Agric Food Chem 48: 849-52.

47. Vinay KK, Kameswara RB, Dilip RM (2010) Effect of Pterocarpus santalinus bark, on blood glucose, serum lipids, plasma insulin and hepatic carbohydrate metabolic enzymes in streptozotocin-induced diabetic rats. Food Chem Toxicol 48(5): 1281-1287.

48. Lemhadri A, Zeggwagh NA, Maghrani M, Jouad H, Eddouks M (2004) Anti-hyperglycaemic activity of the aqueous extract of Origanum vulgare growing wild in Tafilalet region. J Ethn 92(2-3): 251-256.

49. Wadood A, Ghufran M, Jamal SB, Naeem M, Khan A, et al. (2013) Phytochemical analysis of medicinal plants occurring in local area of Mardan. Biochem Analy Biochem 2(4): 1000144.

50. Ganesan P, Phaiphan A, Murugan Y, Baharin BS (2013) Comparative study of bioactive compounds in curry and coriander leaves: An update. I Chem Pharm Res 5(11): 590-594.

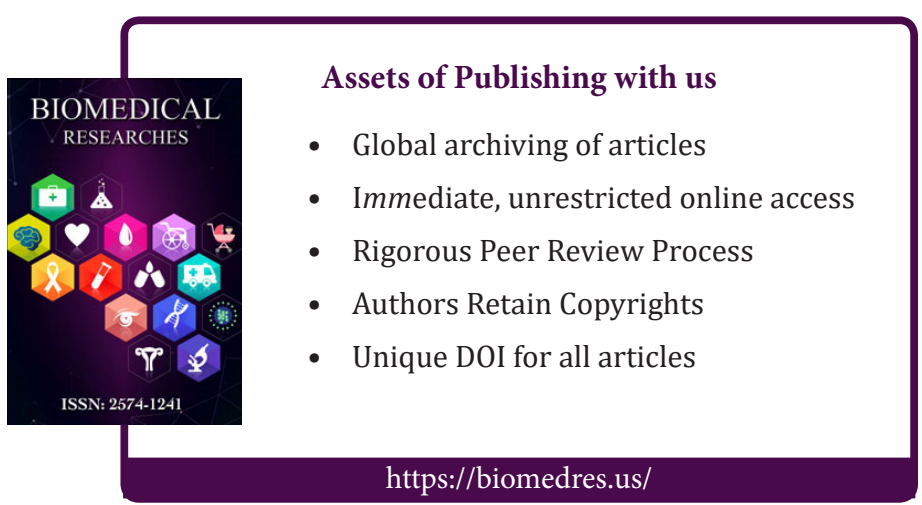

